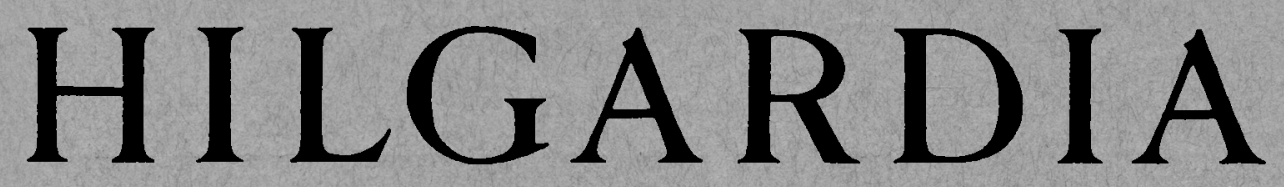

A Journal of Agricultural Science Publisbed by the California Agricultural Experiment Station

\title{
VIRUS-STRAIN INTERFERENCE IN RELATION TO SYMPTOMS OF PSOROSIS DISEASE OF CITRUS
}

\author{
JAMES M. WALLACE
}


The citrus diseases described in literature as psorosis " $A$," psorosis " $B$," concave gum, blind pocket, crinkly leaf, and infectious variegation have been assumed to be caused by related virus strains because they all have the same characteristic symptom on young leaves. All are bud-perpetuated and graft-transmissible but are not known to be transmitted to any extent by other means. On psorosis A trees grown from infected buds, the scaling bark lesions develop after the trees are six or more years of age.

In studies of lesion initiation and symptom expression in relation to source of inoculum, young sweet orange trees infected by means of bark patches taken from non-lesion parts of psorosis A trees showed only the transitory young-leaf symptoms for a period of years. At later times typical, localized lesions of the psorosis A type developed on the inoculated plants. On the other hand, if inoculations result from bark taken directly from a lesion, the test trees react quickly. They show young-leaf symptoms, and bark symptoms begin to arise generally on the trees within three months. Later the mature leaves show rings and blotches, and small twigs die.

Sweet orange trees previously infected with psorosis A from non-lesion sources of inoculum showed no such immediate effects when reinoculated from psorosis $A$ lesion sources. This protective reaction provided a means of testing the relationship of the psorosis virus strains. Trees first inoculated and systemically infected with the viruses of psorosis B, concave gum, blind pocket, crinkly leaf, and infectious variegation were protected as described above when reinoculated from psorosis A lesion bark. This demonstrated virus strain relationship. The quick decline (tristeza) virus provided no protection against psorosis.

Although trees reinoculated as described above are protected to the extent that they do not develop the early, severe symptoms, localized, slowly developing bark lesions develop after a year or more around the sites where the lesion bark inoculum used for reinoculation is introduced. The development of such lesions on trees invaded by virus from the previous inoculation from non-lesion inoculum more or less parallels the occurrence of lesions on orchard trees which normally develop in later years in spite of the fact that the virus has been present at all times. The spontaneous development of lesions on orchard trees and how they are initiated are not fully understood.

From the studies reported in this paper a hypothesis is advanced that psorosis $A$ infected sweet orange trees carry two virus strains or components, one of which (component $a$ ) is capable of producing bark lesions and the other (component b) is not capable of producing lesions. In non-lesions bark, component $a$ is the dominant part of the mixture and prevents component $b$ from increasing sufficiently to bring about the injury that leads to lesion development. Bark lesions are initiated when component b by chance invades one or more plant cells ahead of component $a$. In the absence of $a$, component $b$ increases in concentration and can then invade adjacent tissues and overcome the defense offered by the former. Such a procedure would explain the delayed appearance and slow enlargement of spontaneously developing lesions on orchard trees which have been systemically invaded by psorosis virus for many years. Some experimental evidence is presented to support this hypothesis. 


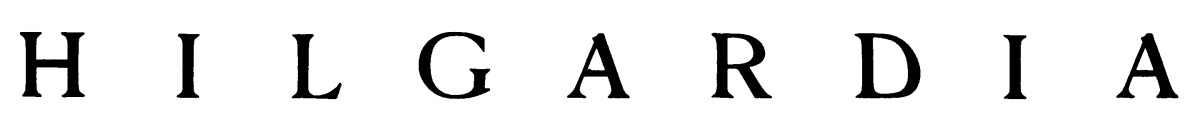

A Journal of Agricultural Science Published by

the California Agricultural Experiment Station

\begin{tabular}{lrr}
\hline Vol. 27 & DECEMBER, 1957 & No. 8 \\
\hline & \\
VIRUS-STRAIN INTERFERENCE IN RELATION TO SYMPTOMS \\
OF PSOROSIS DISEASE OF CITRUS
\end{tabular}

JAMES M. WALLACE

\section{INTRODUCTION}

THE BARK-SCALING disease of citrus now known as psorosis "A" was first described under the name psorosis by Swingle and Webber, in Florida, in 1896 . Prior to that time the disease had been called both gummosis and scaly bark. In 1932, Fawcett designated the commonly occurring type of the disease as psorosis " $\mathrm{A}$ " to distinguish it from a more active or virulent type which he named psorosis "B." Following the discovery of the leaf symptom of psorosis (Fawcett, 1933), and the indication that psorosis "A" and "B" were caused by viruses, the term psorosis was expanded to include three disorders known as concave gum, blind pocket, and crinkly leaf (Fawcett and Klotz, 1938; Fawcett, 1939). Experimental studies at that time demonstrated that these diseases were caused by viruses. A sixth symptomtype of psorosis was described in 1939 by Fawcett and Klotz and was given the name infectious variegation.

In 1943, Fawcett and Bitancourt published a detailed description of psorosis "A," psorosis "B," concave gum, blind pocket, crinkly leaf, and infectious variegation. These authors referred to the first five as "varieties" of psorosis but were uncertain whether or not the infectious variegation type differed sufficiently from crinkly leaf to permit its being described as a distinct "variety."

In view of the results of studies by the writer, some of which will be described in this paper, it seems preferable to refer to the different forms of psorosis as types and to consider that they are caused by strains of the same virus.

\section{SYMPTOMATOLOGY}

The symptoms on young leaves, although somewhat variable within each psorosis type, are the most consistently similar symptoms found throughout the entire group. Small elongated areas distinctly lighter to slightly paler green than the rest of the leaf occur in the region of the veinlets (fig. 1, $A$ ). These areas are usually about 1 to $3 \mathrm{~mm}$ long and 0.25 to $1 \mathrm{~mm}$ broad, the

${ }^{1}$ Received for publication March 12, 1957.

${ }^{2}$ Paper No. 945, University of California Citrus Experiment Station, Riverside.

${ }^{3}$ Plant Pathologist in the Citrus Experiment Station, Riverside.

"See "Literature Cited" for citations referred to in text by author and date. 


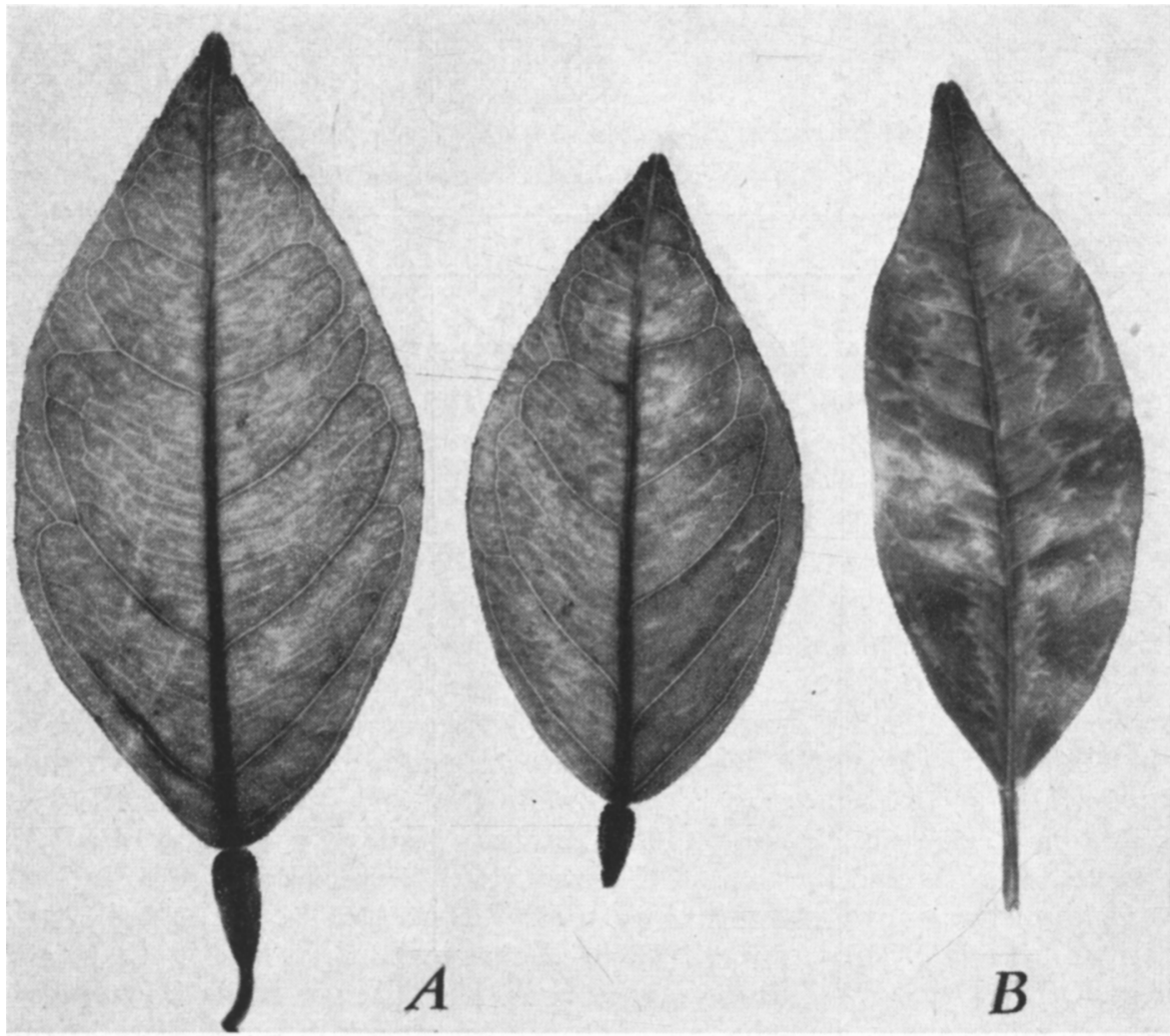

Fig. 1. Psorosis young-leaf symptoms on sweet orange. $A$, typical flecking and vein clearing on soft leaves, a symptom of all the known strains of psorosis virus. $B$, the zonate or oak-leaf pattern which appears regularly on spring growth of trees infected with the concave-gum strain of psorosis virus.

long axis paralleling the main lateral veins. They may be numerous and general over the leaf or comparatively few in number and on only certain parts of the leaf blade. In some instances the cleared areas may coalesce to form larger blotches. The young-leaf symptoms become indistinct and disappear as the leaves mature.

The different psorosis types cannot be identified on the basis of the young-leaf symptoms except that in the spring or early-summer growth flushes nearly all affected leaves on sweet orange trees infected with concavegum psorosis display a zonate, or oak-leaf pattern (fig. 1, $B$ ). However, the young leaves of later-growth flushes on the same trees show very few or none of these patterns. Identification of the various psorosis types usually is possible only after other symptoms, or secondary effects, have made their appearance.

Psorosis "A". This is by far the most common type of psorosis. It is characterized by bark lesions which usually begin to develop after infected 

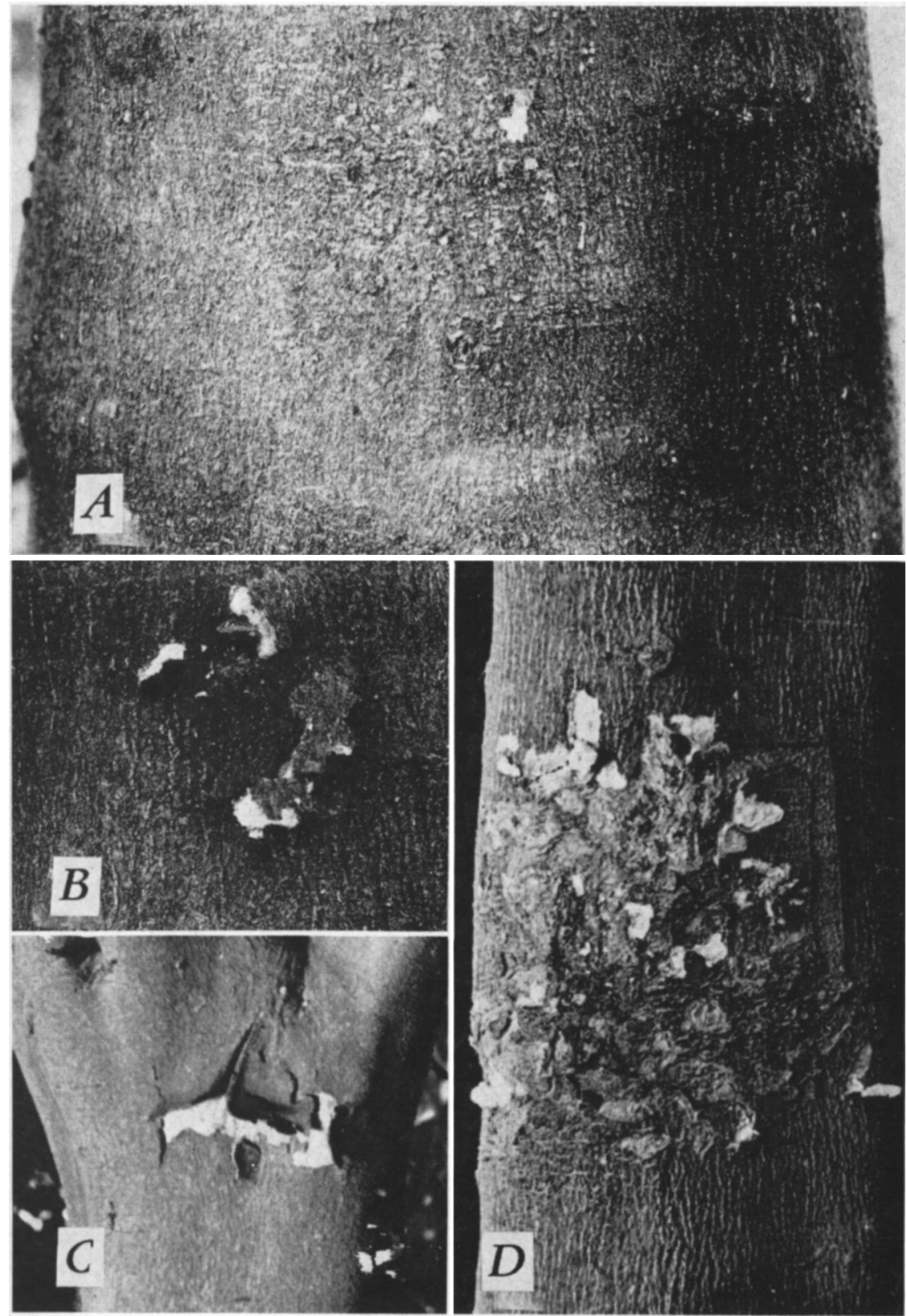

Fig. 2. Psorosis "A." Different stages in the development of bark symptoms on trunks of sweet orange trees. $A$, early stage: small, pimply eruptions. $B$ and $C$, early stages of scaling. $D$, later stage of scaling. (Photos by L. J. Klotz.) 


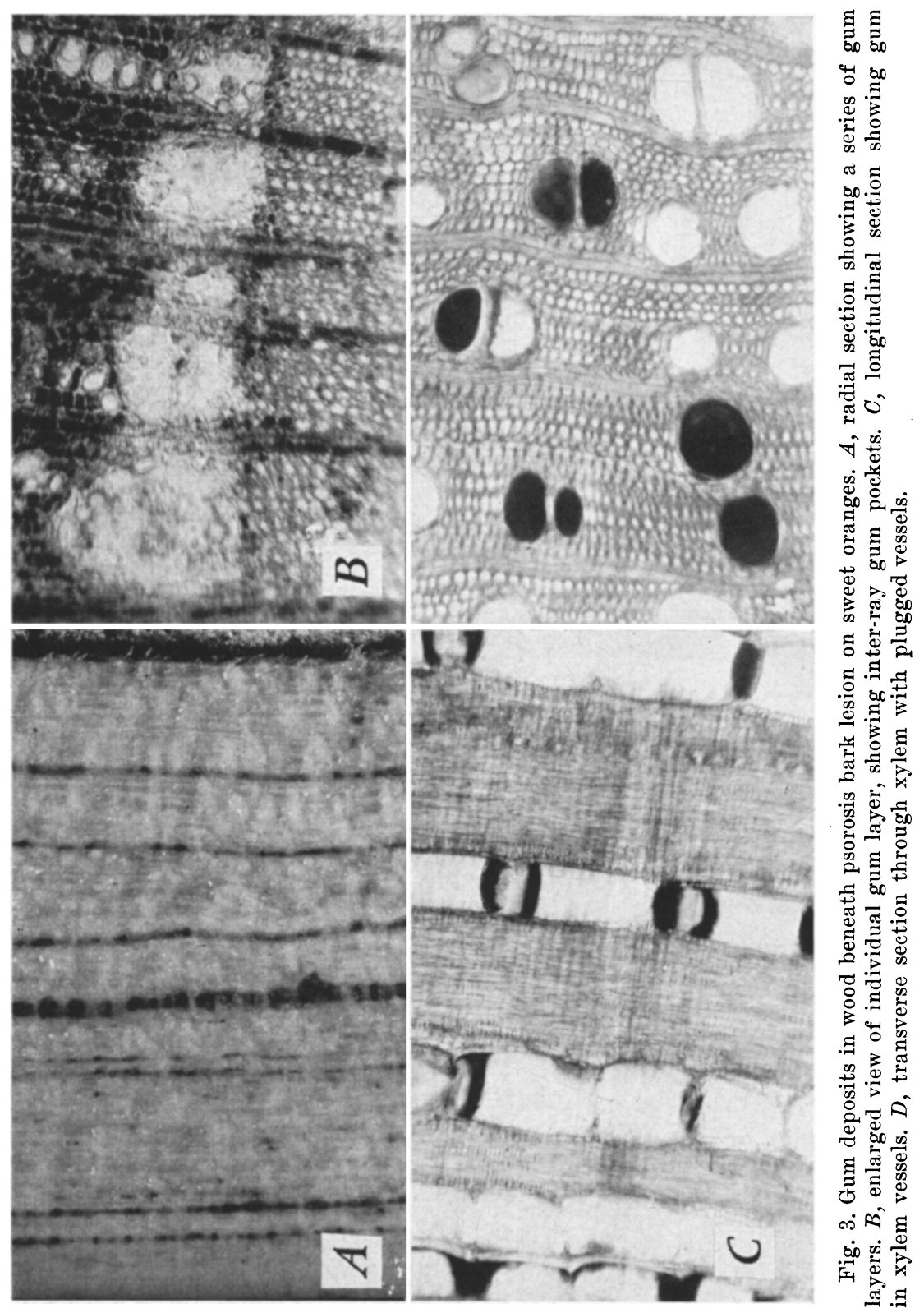


trees attain an age of ten years or more. The citrus species most severely affected by psorosis "A," in respect to bark symptoms, are sweet orange, Citrus sinensis (Linn.) Osbeck; grapefruit, C. paradisi Macf.; and tangerine, C. reticulata Blanco. Numerous other species show typical leaf symptoms when infected but remain free of bark lesions. Sweet orange trees developed from buds of trees infected with psorosis " $A$ " have not been known to develop bark lesions in less than five years from time of budding. On some infected trees, bark lesions do not appear during the first twenty to twenty-five years of the life of the trees. Lesions usually occur first on the trunk or primary limbs of the tree, where one lesion or several may begin at about the same time. The lesions may remain few in number or may continue to appear in varying numbers on a given tree. They usually increase in size rather slowly, but some show more activity than others. On certain trees, large numbers of separate lesions may eventually be present, some of them on small limbs or twigs.

Bark lesions of psorosis "A" first appear as very small pimply eruptions (fig. 2, A). Scaling of the outer bark in dry, irregular flakes follows. As the lesions enlarge, gum may exude from the affected area, mostly at the margin or somewhat in advance of the bark shelling. More advanced stages of lesion development are shown in figure $2, B, C, D$. Soon after the appearance of bark lesions, gum layers can be observed in the xylem immediately adjacent to the cambium. Normal wood growth proceeds for a time and is followed by the production of another gum layer. This process continues, with the older gum layers becoming more deeply buried in the xylem as new bands of normal wood develop (fig. $3, \boldsymbol{A}, \boldsymbol{B}$ ). During this time gum plugs appear in the xylem vessels (fig. $3, C, D$ ). At later stages the xylem tissues become impregnated with gum and the wood-stain stage of psorosis " $\mathrm{A}$ " becomes apparent. After the appearance of these secondary wood symptoms, the affected trees deteriorate rather rapidly. Deterioration results largely from blockage of water-conducting tissue.

Psorosis "B." This type of psorosis has been described by Fawcett and Klotz (1938), Fawcett and Bitancourt (1943), and Klotz and Fawcett (1941) as differing from psorosis " $A$ " by having more extensive and more rapidly developing areas of bark scaling, more numerous lesions on small limbs and twigs, a variety of persistent patterns on mature leaves, and rings or other markings on fruits. It is now known that all these symptoms can be reproduced by transplanting a section of bark directly from a typical psorosis-"A" lesion to a healthy, psorosis-free sweet orange tree. In view of these developments, psorosis " $\mathrm{B}$ " is now considered to be a symptom type rather than a distinct strain of psorosis virus. As will be brought out later in this paper, if the psorosis-" $\mathrm{B}$ " reaction is caused by a distinct virus strain, this strain apparently always exists as a mixture with psorosis "A."

In the discussion to follow, the more or less localized, slowly enlarging bark lesions which arise spontaneously on trees some years after they have been infected are referred to as the typical psorosis-" $A$ " lesions. On the other hand, the general, rapidly developing bark lesions accompanied by mature-leaf symptoms, killing of areas of bark, and twig and limb dieback 
[Vol. 27, No. 8
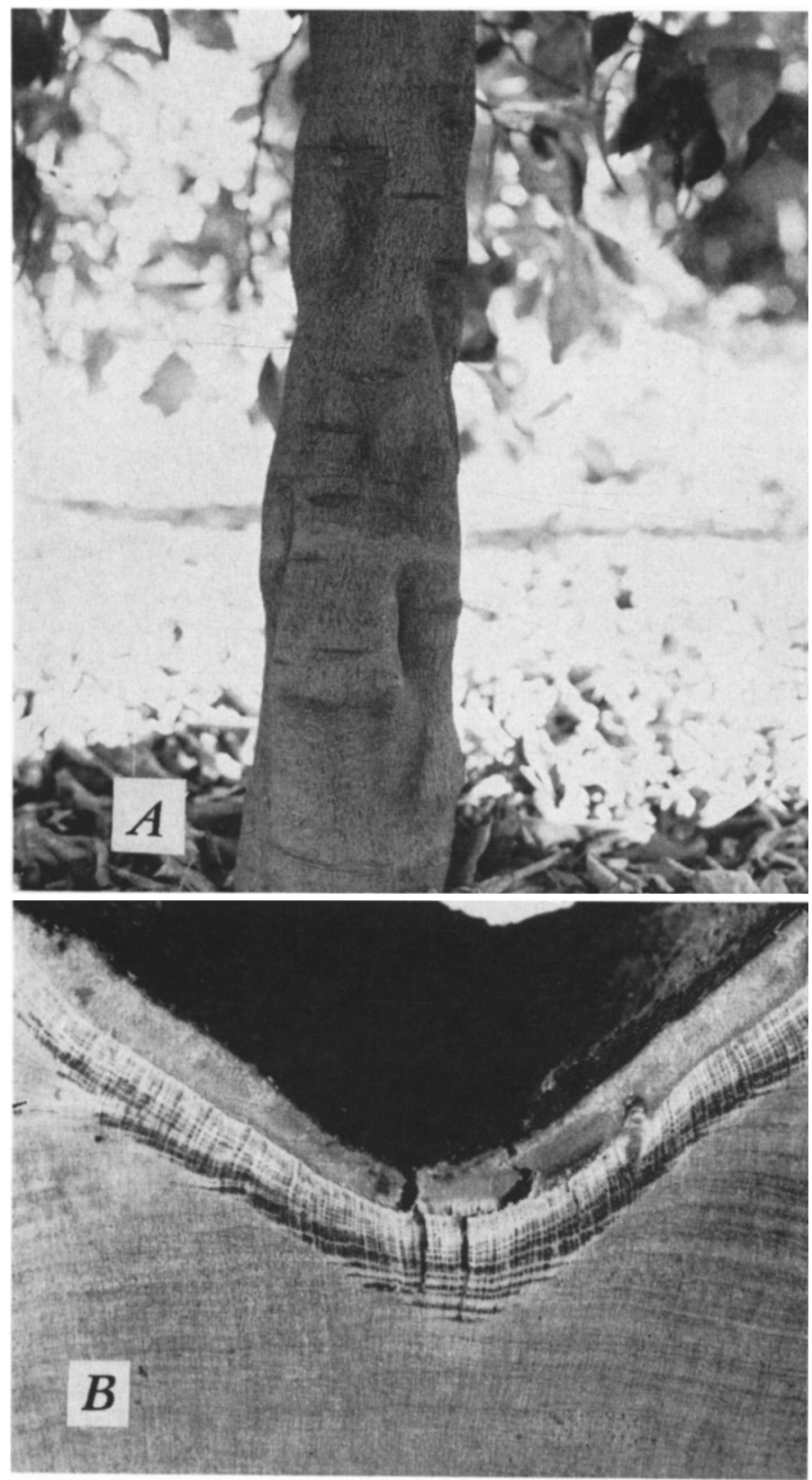

Fig. 4. Effect of concave-gum psorosis on bark and wood of sweet orange tree. $A$, concavities and irregular wood growth. $B$, section through a concavity showing gum layers in outer xylem. 


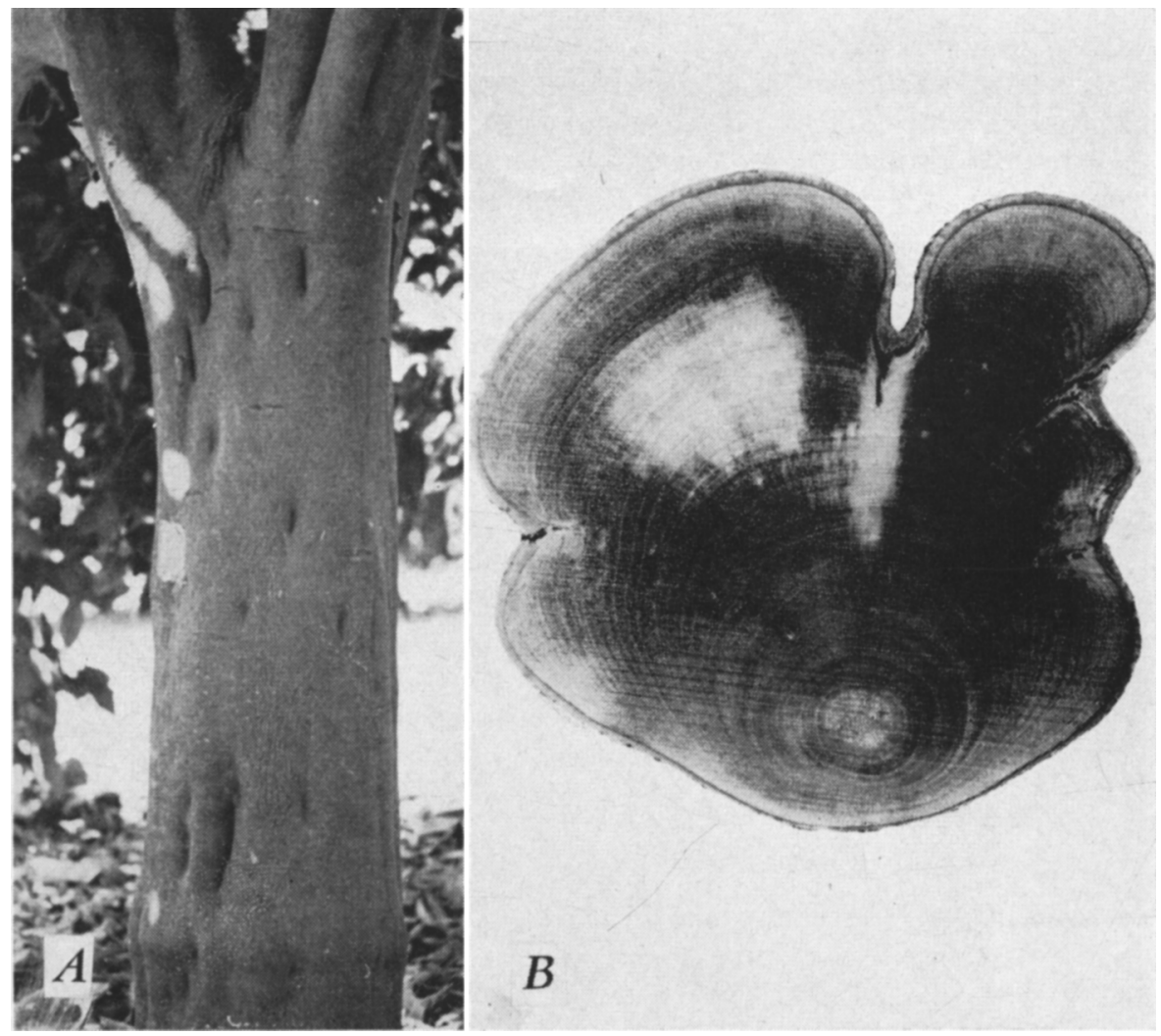

Fig. 5. Blind-pocket psorosis on sweet orange tree. $A$, tree trunk, showing numerous blind pockets. $B$, transverse section through blind pockets on limb. Wood section had been stained with IKI to show starch distribution.

are the severe reaction symptoms which develop when psorosis-free sweet orange trees are infected from lesion bark and are descriptive of the psorosis"B" reaction type.

Concave Gum. Concave-gum psorosis is characterized by the development of concavities resulting from the inhibition of wood growth in localized regions of the trunk or large limbs (fig. $4, A, B$ ). There is no regularity in time of appearance in relation to age of trees or in the numbers of concavities developing on an infected tree. Some of the xylem vessels become plugged with gum, and gum layers formed in the wood beneath the concavities are similar to those of psorosis "A" but are more localized. There is no bark scaling, and the wood does not develop the secondary staining.

Blind-pocket. This type of psorosis is characterized by depressions similar to those of concave gum, except that they are narrower and more numerous (fig. 5, $A, B$ ). Gum layers are formed as in concave gum, and some of the vessels are plugged with gum. Underneath the depression there is an area 
in which the wood parenchyma is somewhat disorganized and impregnated with a gummy substance.

Crinkly Leaf. In addition to the usual young-leaf symptoms, this strain of psorosis virus induces a persistent warping or pocketing of leaves (fig. 6 ). It is mainly evident on lemon, Citrus limon (Linn.) Burm., where it also causes some of the fruit to be small and irregularly shaped. It causes no

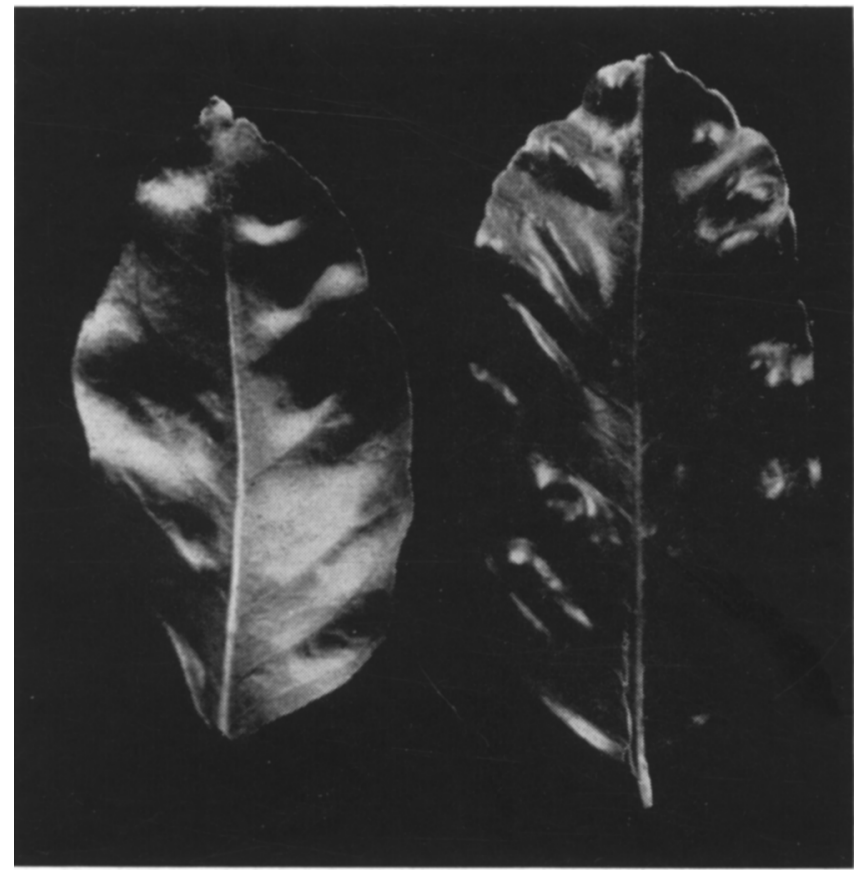

Fig. 6. Crinkly-leaf psorosis. Mature leaves of lemon showing characteristic pocketing or crinkle. (Photo by L. J. Klotz.)

distinctive bark or wood symptoms on lemon, but sweet orange trees infected with this strain of virus develop bark lesions like those of psorosis "A."

Infectious Variegation. This type of psorosis, which Fawcett and Bitancourt (1943) considered to be closely related to crinkly leaf, is not encountered often in California. While it causes some leaf effects resembling those of crinkly leaf it also induces marked variegations on leaves of lemon and sour orange, Citrus aurantium Linn. (fig. 7, A, B). Whether or not this strain of psorosis induces bark lesions has not yet been determined.

\section{TRANSMISSION OF PSOROSIS VIRUS}

Psorosis virus has been transmitted experimentally by means of tissue grafting only. Field studies show no significant amount of natural spread of the virus by insect vectors or other means, and all efforts to transmit the virus mechanically have failed. Only the crinkly-leaf strain of virus 
has been demonstrated to be seed-transmitted, and passage through seeds has been observed in only rare instances. Natural grafts between roots of diseased and healthy trees sometimes take place, and a healthy tree can become infected in that way. For the most part, however, diseased orchard trees have resulted from the use of infected trees as sources of budwood in the propagation of young trees. Trees grown from infected buds become systemically invaded by the virus, display young-leaf symptoms more or less regularly, and in later years, depending on the psorosis strain present and the susceptibility of the host species, develop the characteristic bark and wood abnormalities.
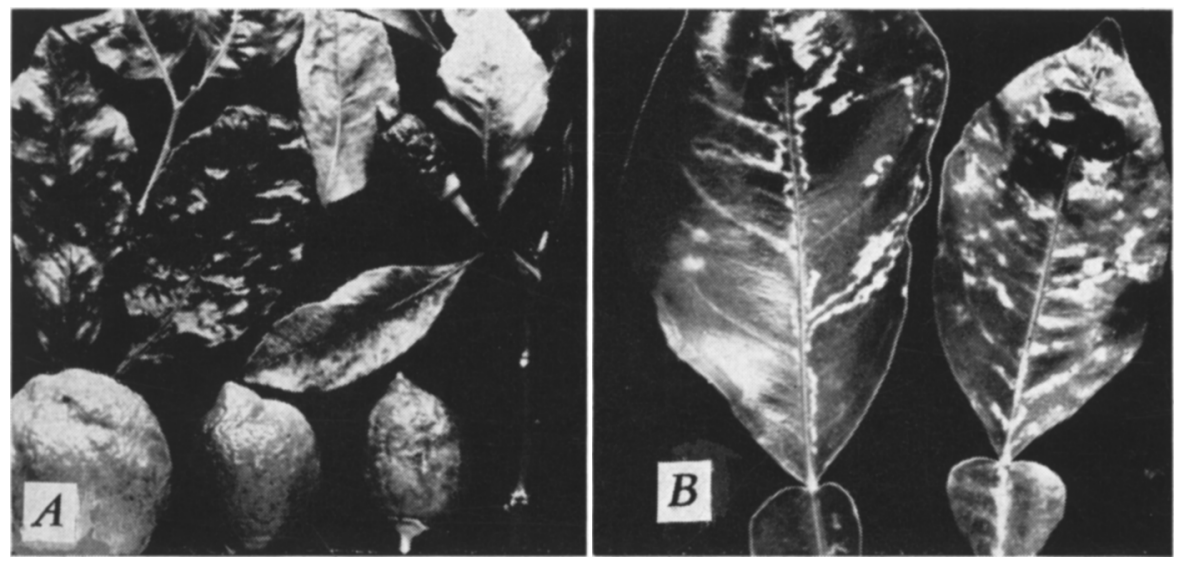

Fig. 7. Infectious variegation. $A$, crinkling and slight variegation of leaves and malformation of fruits of lemon, caused by this strain of psorosis virus. $B$, variegated patterns on leaves of sour orange. (Photos from Kodachromes by L. J. Klotz.)

The manner in which the bark lesions or the concavities are initiated, the time of their appearance in relation to the age of the trees, and the variations between individual trees in the number and activity of lesions have been given much study but as yet remain unexplained.

\section{HOST REACTION INFLUENCED BY KIND OF INOCULUM}

Fawcett and Cochran (1942) first observed that sweet orange seedling trees infected with psorosis "A" by means of bark transplanted directly from a lesion responded differently from trees infected by means of non-lesion bark. Trees infected from lesion inoculum developed bark symptoms within five months, whereas trees given inoculations from normal bark taken 3 to 5 inches from the margin of the lesion developed no early bark symptoms. Since the early observations of Fawcett and Cochran, the writer has repeatedly corroborated their findings and has made additional observations on host response in relation to kind of inoculum.

The psorosis virus can be graft-transmitted by means of leaf tissue (Wallace, 1945, 1947) bark patches, buds, or scions. Infection from normalappearing bark of psorosis-"A" trees results in young-leaf symptoms on 


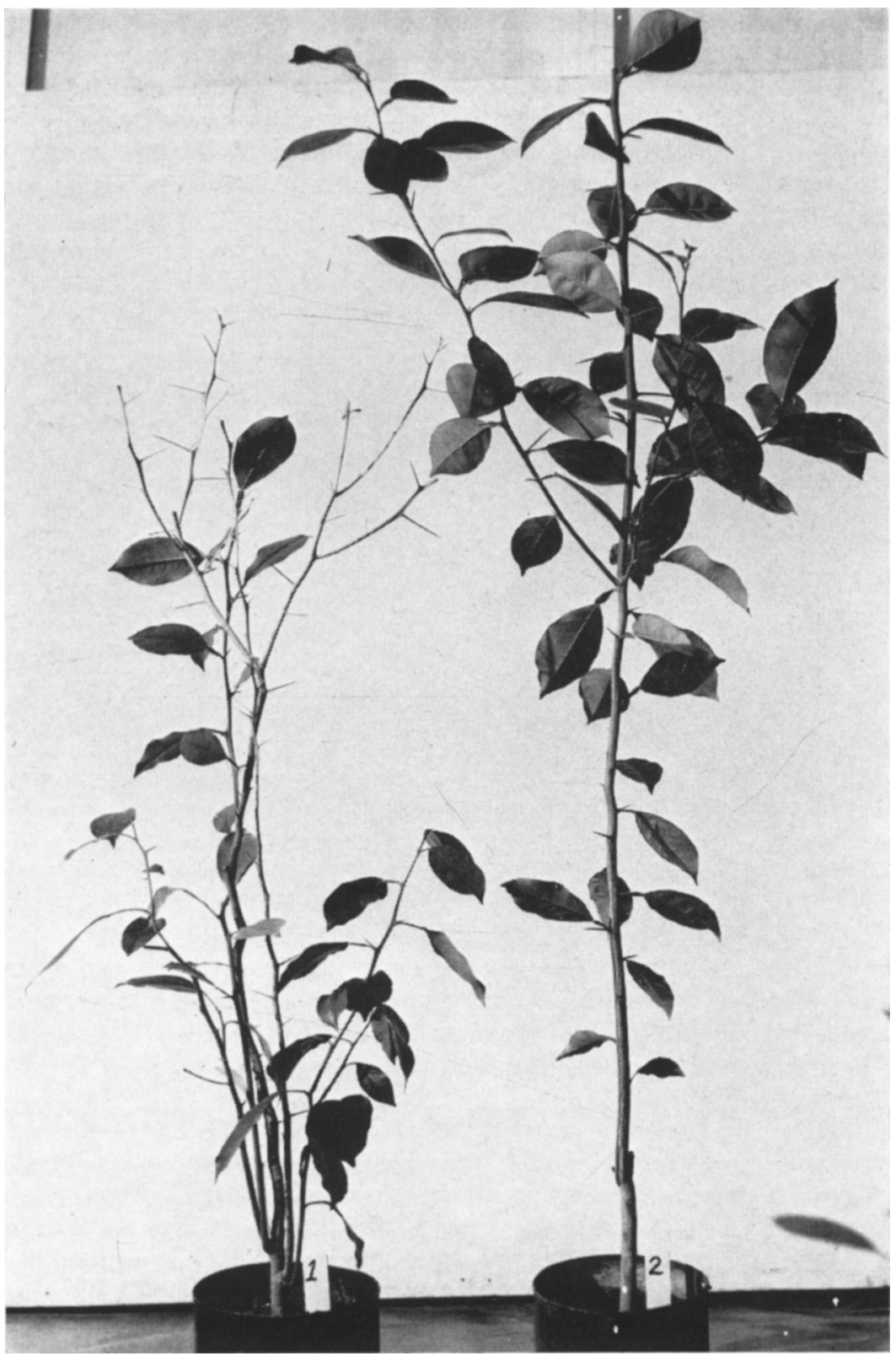

Fig. 8. Reactions of sweet orange seedlings to infection with psorosis from different kinds of inoculum. Plant 1 infected by lesion-bark transplant shows dieback from earlydeveloping, general bark lesions. Plant 2 infected by non-lesion-bark transplant displayed young-leaf symptoms only. 
inoculated seedling trees after about four weeks. Trees infected in this way will continue to show the young-leaf symptoms quite regularly during periods of new leaf growth. After five years or longer, localized, slowly enlarging bark lesions begin to appear. Non-lesion bark transfers from these trees to healthy trees again give the reactions described above. The same results are obtained when inoculations are made from any psorosis-" $\mathrm{A}$ "infected tree, regardless of its age or the presence or absence of bark lesions, if the tissue used for inoculation is from non-lesion areas.

Infection from bark taken directly from a psorosis-"A" lesion likewise causes young-leaf symptoms to appear shortly afterward. Additionally, on small sweet orange seedlings one to two years of age, bark symptoms sometimes begin to develop within two months after inoculation. The bark symptoms gradually develop over the entire plant and continue to spread onto new growth as it develops. Some parts of the original tree often show severe dieback. Later, mature leaves display the persistent spots, blotches, and rings described earlier by Fawcett and Klotz (1938) and by Fawcett and Bitancourt (1943). The bark lesions that develop on healthy trees infected from lesion inoculum differ from typical psorosis-" A" lesions which develop spontaneously on orchard trees propagated from diseased trees or on trees experimentally infected by means of non-lesion inoculum. Instead of developing slowly in localized areas the lesions develop rapidly over the entire tree.

Figure 8 shows a sweet orange seedling (plant 1) after infection from lesion inoculum, in comparison with plant 2, which was infected from non-lesion inoculum. Severe dieback and bark symptoms were present generally on plant 1 . Plant 2 displayed young-leaf symptoms, but no other effects. These reactions are typical of young sweet orange trees inoculated by means of lesion and non-lesion bark grafts.

After these two reaction types are established, as described, transfers from the respective types to healthy sweet orange seedlings will duplicate the reactions; that is, lesion inoculum from the severely affected seedlings results in the severe reaction and inoculum from the infected but lesionfree seedlings causes the mild response. However, when trees are older and not pruned back when inoculated, individual limbs of those infected from lesion inoculum sometimes remain free of bark and mature-leaf symptoms. When transfers are made from such growth the resulting infection is of the mild type with no early general bark symptoms.

On the other hand, if a mildly affected tree such as tree 2 of figure 8 is grown for a period of years until localized bark lesions develop spontaneously, transfers from these lesions will again result in severe reaction, but transfers from non-lesion parts of the same tree will cause only mild reaction.

\section{CROSS PROTECTION OR VIRUS-STRAIN INTERFERENCE}

Fawcett (1939), and Fawcett and Bitancourt (1943), assumed that psorosis "A," psorosis "B," concave gum, blind pocket, crinkly leaf, and infectious variegation were caused by related virus strains. The bases for the supposed relationship were the identical means of transmission, the similarity in host range, and the common, characteristic symptoms on young leaves (Fawcett and Bitancourt, 1943). 


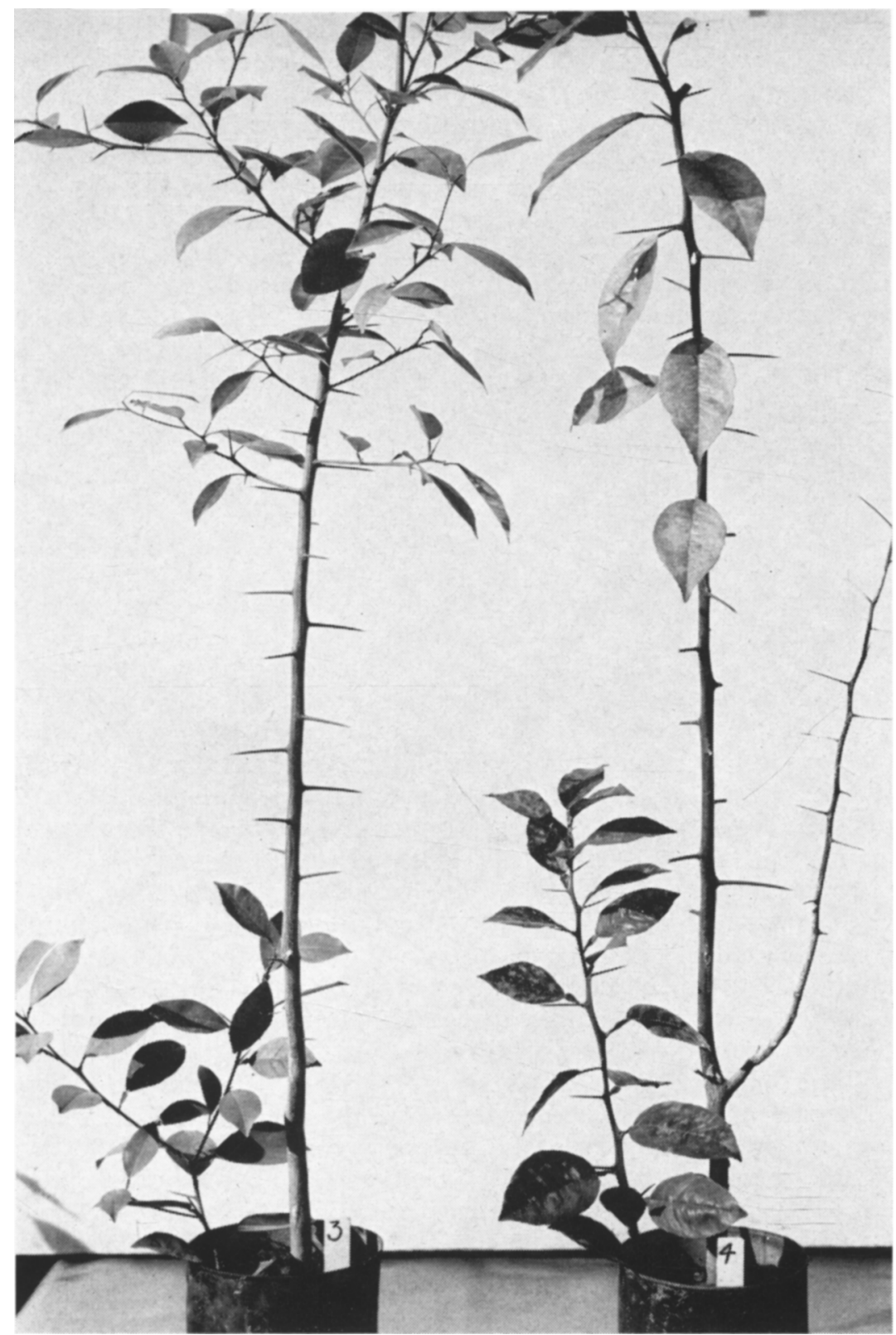

Fig. 9. Cross protection or interference reaction in citrus. The response of a sweet orange seedling tree (plant 3) previously infected from non-lesion inoculum and of a healthy tree (plant 4) to inoculations from lesion bark. Plant 3 was not affected when reinoculated with psorosis "A" lesion inoculum which caused the mature-leaf symptoms, and twig dieback shown on plant 4. (Photographed 22 months after introduction of lesion inoculum.) 
This paper describes a cross-protection reaction which demonstrates experimentally that the different psorosis types are caused by related virus strains. This particular interference phenomenon is of additional interest because it involves the two different symptom manifestations described above.

Cross-protection Phenomenon. Sweet orange seedlings previously infected from non-lesion inoculum of psorosis " $\mathrm{A}$ " showed no immediate effects when reinoculated with lesion inoculum of this same strain. In other words, lesion inoculum which caused the early general bark symptoms, mature-leaf symptoms, and twig dieback on healthy trees produced none of these symptoms on young seedling trees which were already systemically infected by a prior inoculation from non-lesion sources. Plants 3 and 4 of figure 9 represent, respectively, the reactions of an infected tree and of a healthy tree to inoculations from lesion bark. Plant 3 had been infected previously by means of a bark transplant from a non-lesion source and was not affected when reinoculated with lesion inoculum. The same lesion inoculum caused the severe general reaction shown on plant 4.

To determine whether the other psorosis strains would provide this same protection, sweet orange seedlings were inoculated and infected singly with concave gum, blind pocket, crinkly leaf, and infectious variegation. When such seedlings were reinoculated by means of lesion bark, they displayed the same protection phenomenon described for psorosis "A." Thus relationship of the various psorosis virus strains was demonstrated experimentally.

In a few instances, particularly with the crinkly-leaf strain of psorosis, protection was only partial. This is unexplained, but it might result from a low concentration and uneven distribution of the crinkly-leaf virus in individual plants, permitting the virus of the second inoculation to become established in sufficient concentrations to overcome, in part, the protection provided by the first infection.

Cross-protection tests showed that the tristeza virus provides no protection against psorosis and is therefore not a closely related virus. Other citrus viruses have not yet been studied in this connection, but the protection test has been applied on numerous occasions to determine the nature of certain psorosis-like abnormalities in citrus, particularly in studies on seed transmission of the psorosis virus. At times, leaf effects or patterns which resemble those of psorosis are encountered in experimental material, and the cross-protection test has been used to determine whether such material is, or is not, infected with psorosis virus.

Spontaneous and Induced Lesions on Orchard Trees. After repeated tests had demonstrated that cross protection operated as described, the question arose as to why bark lesions develop spontaneously on psorosisinfected orchard trees. In the absence of natural spread of the virus it can generally be accepted that diseased orchard trees have been propagated from psorosis-infected budwood sources and have therefore been systemically invaded by the virus throughout their lifetime. On the basis of the experimentally demonstrated cross protection, it would thus seem that bark lesions should not develop on such trees.

Bark lesions which develop naturally on orchard trees are localized. Once 


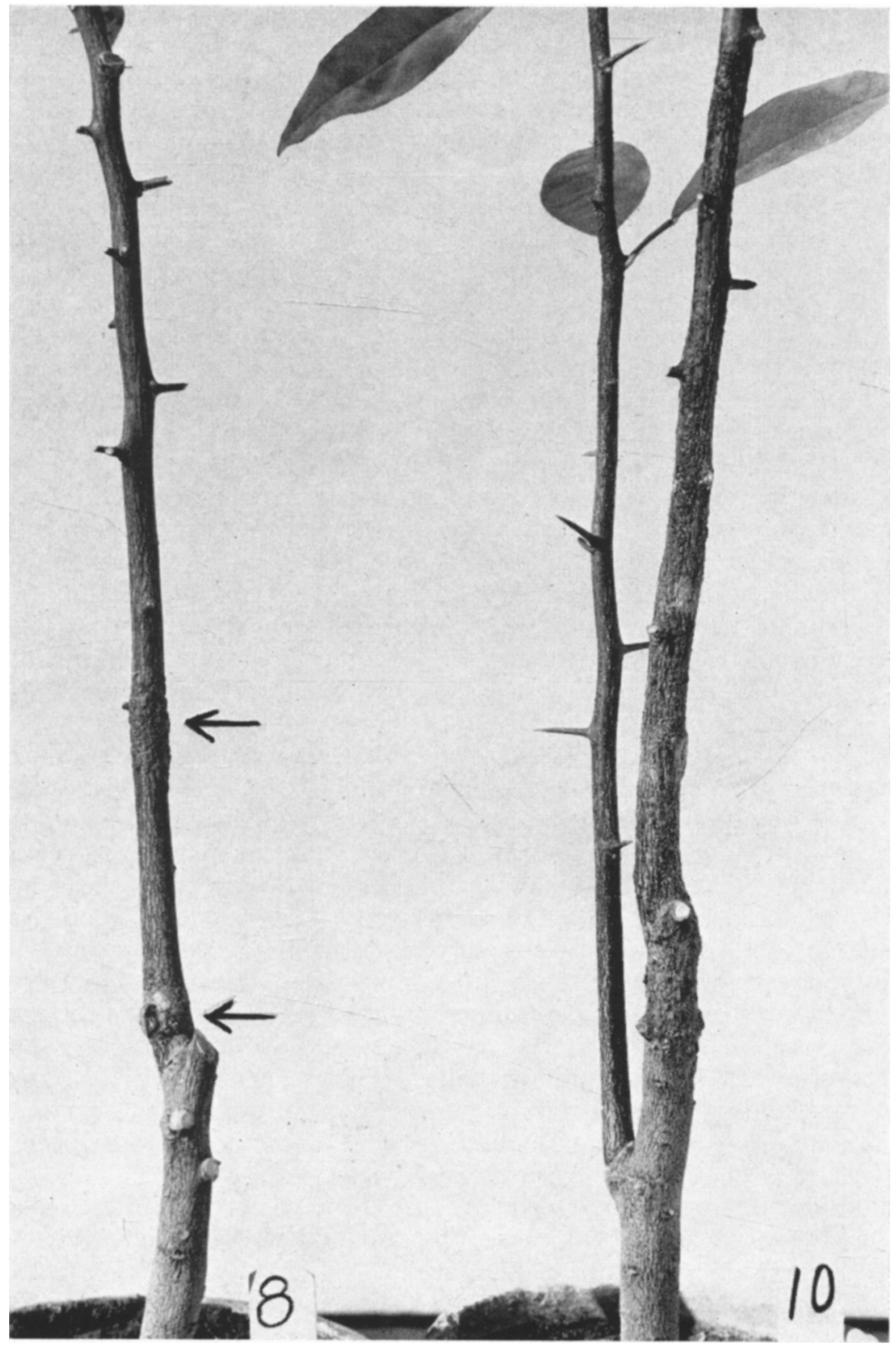

Fig. 10. Bark lesion development on protected and non-protected sweet orange seedling trees. Plant 8 , first infected with the virus of psorosis " $\mathrm{A}$ " from non-lesion inoculum and then reinoculated with lesion inoculum, shows localized lesions around sites of inoculation (see arrows). The lesions did not become apparent until two years after reinoculation. Plant 10 shows general bark lesion development on a healthy plant infected from the same inoculum used on plant 8. (Photographed four years after introduction of lesion inoculum.) 
initiated the lesions usually enlarge slowly and uniformly. On the other hand, the lesions appearing after a healthy tree has been infected from bark-lesion inoculum develop quickly and over the entire tree. Thus it seems that bark lesions which arise spontaneously on orchard trees remain localized because of a protective action of virus systemically distributed throughout the tree. However, this provides no explanation as to why the protection is not sufficient to prevent lesion formation entirely, as it was apparently in experimentally reinoculated trees.

For further study of lesion types and their initiation, sweet orange seedlings that had been infected from non-lesion inoculum and had not reacted when reinoculated with lesion inoculum were retained for a period of years. The purpose was to determine whether such trees would develop bark lesions at a later time. These studies demonstrated that on some of the reinoculated trees, localized bark lesions began to develop within one and one-half years; on others, no lesions have appeared in four years. In all instances of lesion development, however, activity has begun directly at the point of reinoculation. Plant 8 (fig. 10) shows the localized lesions developing around the points of reinoculation. This seedling was infected first from non-lesion inoculum, and was then reinoculated with lesion inoculum. The localized bark lesions began to appear two years after the second inoculation. Plant 10 (fig. 10) was healthy prior to its inoculation with the same lesion inoculum used on plant 8 and shows the general bark-lesion development of a non-protected plant.

The later development of the localized bark lesions on the previously invaded trees, which were protected against the early severe reaction when reinoculated, served to make less puzzling the naturally occurring lesions on orchard trees. Although the localized bark lesions in both instances are apparently identical, there remains one difference in regard to their initiation or origin. It is clear that the later-appearing bark lesions on reinoculated trees result from the reinoculation, whereas on diseased orchard trees the lesions arise without any additional inoculation. Figure 11 shows the reactions of sweet orange seedlings infected from lesion and non-lesion inoculation of psorosis "A," the cross protection in seedlings previously infected from non-lesion inoculum, and the delayed development of localized bark lesions around the sites of reinoculation.

In order to study the cross-protection reaction on older trees, bark-lesion inoculations were made on fifteen-year-old sweet orange trees in field plantings. Healthy trees and trees which were known to have been infected with psorosis-"A" virus for many years, but which had not yet developed bark lesions, were used. Bark patches about $1 \times 2 \mathrm{~cm}$ in size were transplanted from a psorosis-"A"-type lesion to paired infected and healthy trees. The results were much the same as with young seedling trees. The virus-free trees responded within two to three months by the production of gum and rupture of the bark near the points of inoculation. Lesion development followed over much of the trunk and primary limbs. Figure 12 shows the condition of a previously healthy tree two years after it was infected by inoculum from lesion bark. 


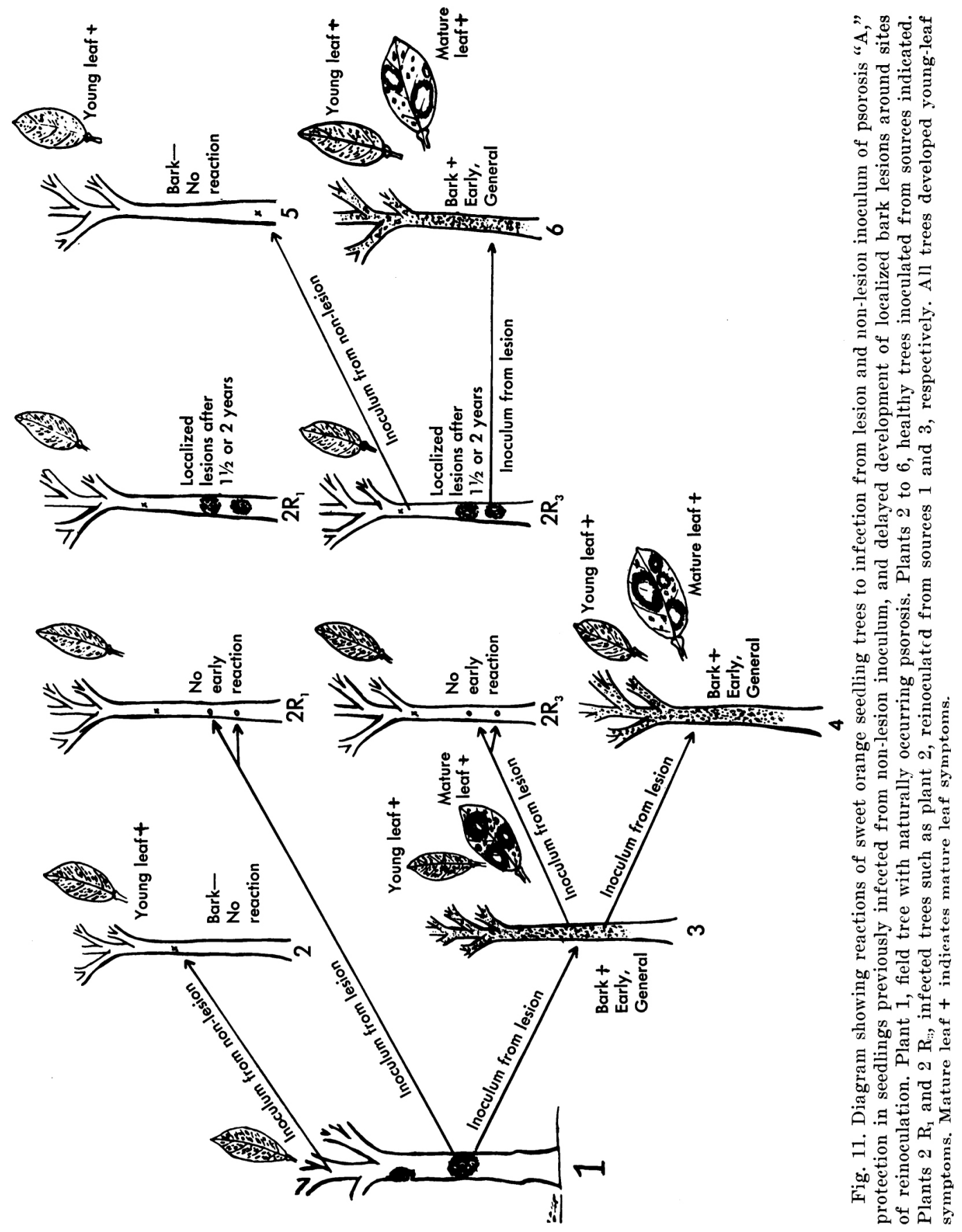




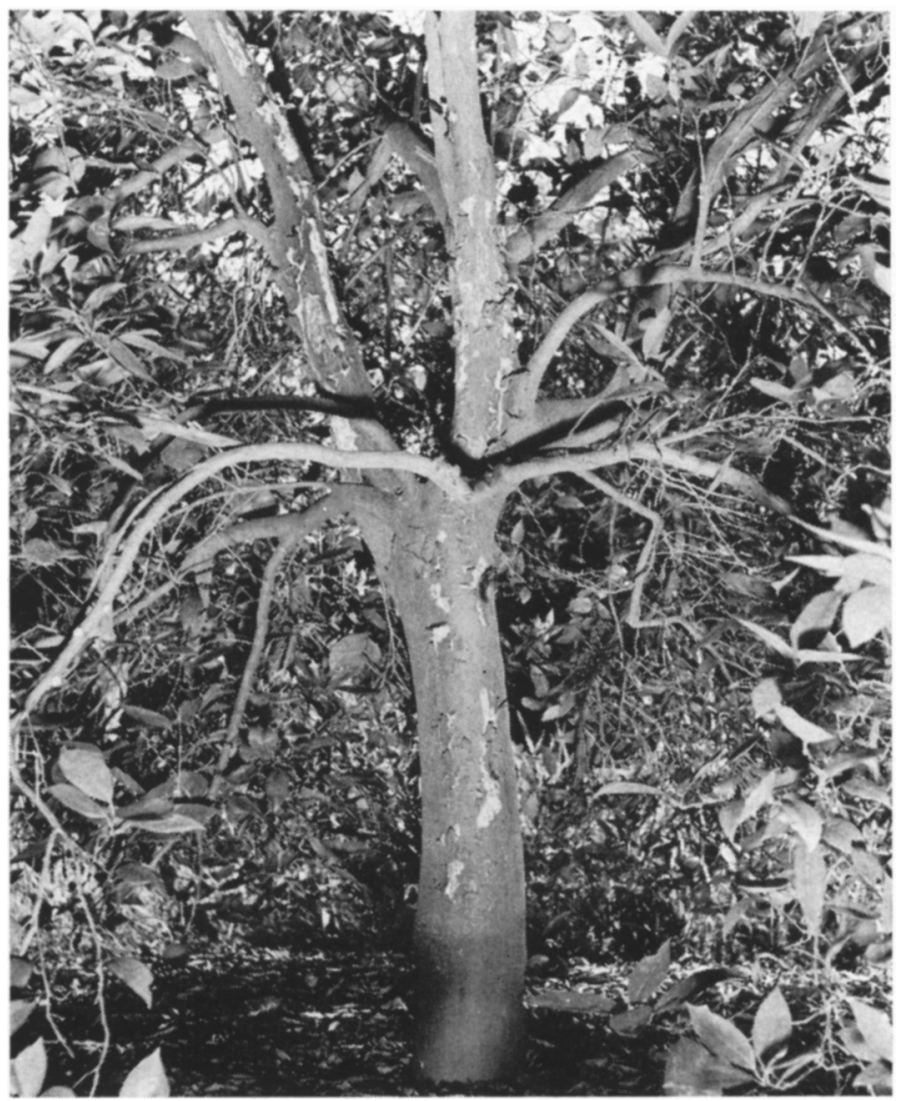

Fig. 12. Extensive bark lesion development on a previously healthy sweet orange tree inoculated by means of a small piece of bark transplanted from a psorosis " $\mathrm{A}$ " lesion. (Photographed two years after inoculation.)

The trees that were already invaded by psorosis virus when reinoculated remain normal for a period of two years, as shown in figure 13, A. Two years or more after reinoculation, as in the experiments with younger trees, localized bark lesions began to develop around the reinoculation sites. The initial stages of such a lesion are illustrated in figure 13, B. These lesions seemed to be identical with those which arise normally on orchard trees, but without question they had been initiated by the transplanted lesion bark.

Experimental production of localized bark lesions by reinoculation of mature trees already systemically infected demonstrated that such lesions can develop in spite of the presence of virus throughout the trees. Thus the results were quite in agreement with the sequence of symptoms on infected orchard trees, that is, naturally occurring bark lesions arising in later years on trees propagated from diseased sources and thus infected from the beginning. 

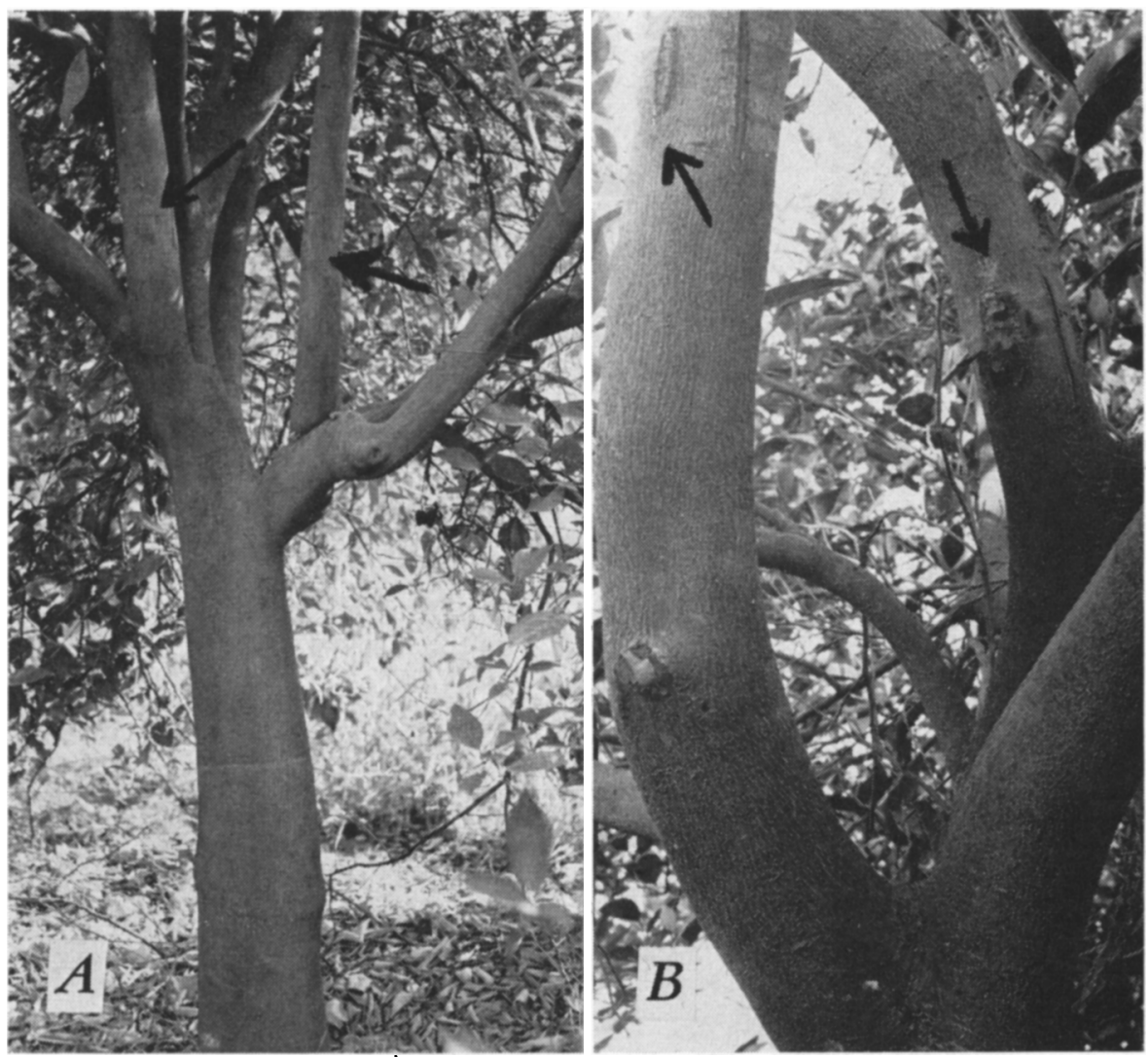

Fig. 13. $A$, sweet orange tree previously infected from a non-lesion source of inoculum of psorosis "A" and then reinoculated from lesion bark. $B$, close-up of another reinoculated tree, showing localized bark lesion beginning to develop around one reinoculation site. Arrows indicate reinoculation sites on both trees. (Trees photographed two years after reinoculation.)

Experiments with Lemon Trees. Lemon trees have never been observed to develop bark lesions of psorosis, regardless of the type of inoculum used. It was therefore of interest to use lemon trees in further studies of the protective reaction.

Budded trees of lemon tops on sweet orange rootstock inoculated by transplanting psorosis-" $\mathrm{A}$ "-lesion bark to the lemon trunks developed only young-leaf symptoms. However, within a few months after inoculation, the sweet orange rootstock developed general bark symptoms. This demonstrated that the virus moved downward through the lemon tissues in sufficient quantity or quality to cause the early production of bark lesions on the sweet orange trunk below the bud union. Sweet orange seedlings inoculated from the lemon portions of these trees displayed young-leaf symptoms of psorosis but developed no early bark symptoms. Thus transfers from lemon growing on a sweet orange rootstock having psorosis bark lesions 
gave the same results as transfers from non-lesion parts of sweet orange trees having localized bark lesions.

Further studies of the response of lemon in relation to kind of inoculum revealed the interesting reactions diagrammed in figure 14 . Lemon trees inoculated from lesion bark of a psorosis."A"-infected sweet orange tree develop only the young-leaf symptoms. If transfer is made from such lemon

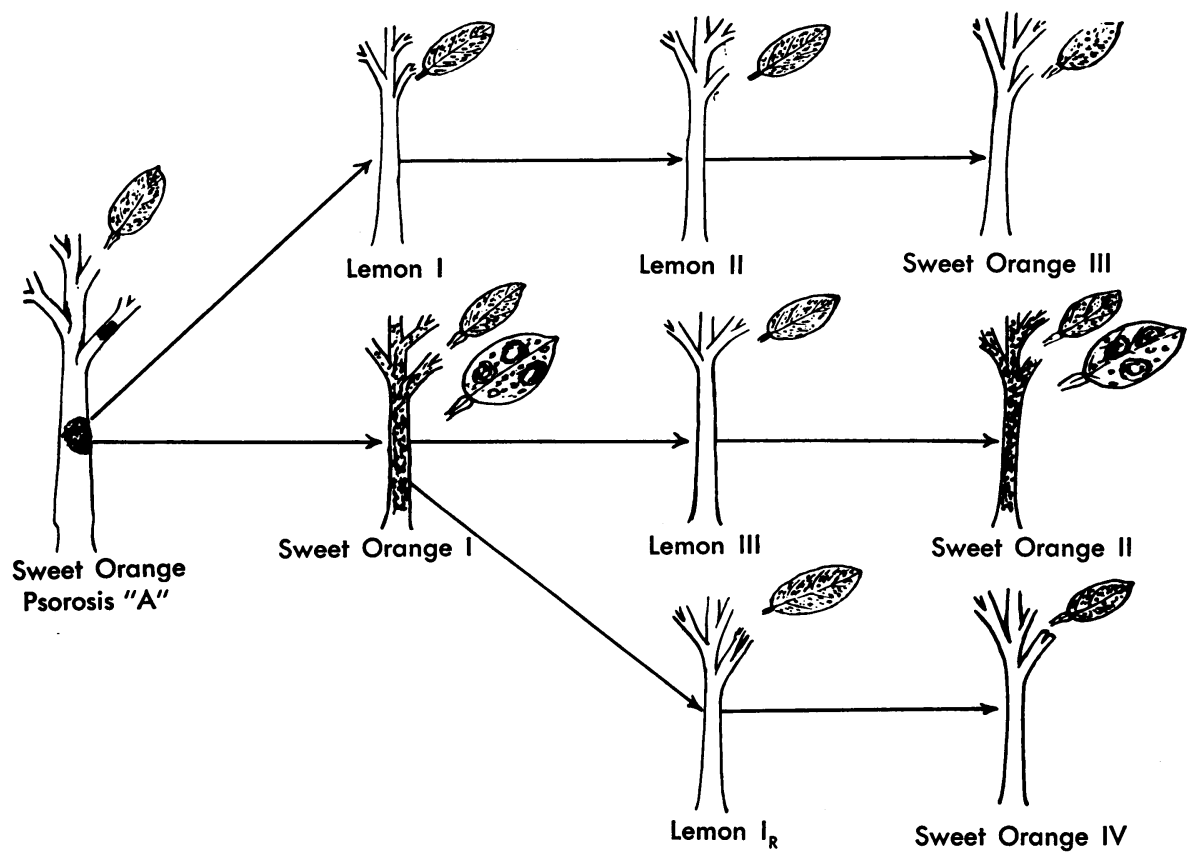

Fig. 14. Diagram showing reaction of lemon seedlings to inoculations from two lesion types of psorosis "A" and demonstrating that cross protection (virus-strain interference) also operates in lemon. Lemon I, II, and III, and Sweet Orange I, II, III, and IV represent trees that were healthy when inoculated from the sources indicated. Lemon $I_{R}$ represents Lemon I reinoculated from Sweet Orange I.

trees to sweet orange, no early general bark lesions develop on the latter (fig. 14, sweet orange III). On the other hand, if psorosis-" $\mathrm{A}$ " inoculum from a localized lesion on sweet orange is first put into a sweet orange seedling to produce the severe general reaction, transfers from such sweet oranges through lemon to healthy sweet orange result in severe symptom reactions on the latter (fig. 14, sweet orange II). In other words, the lemon tree responds differently to different kinds of inoculum. Infection of lemon seedlings from the two inoculum sources described gave identical symptoms on lemon, but subsequent transfers to sweet orange seedlings demonstrated that the concentration or, possibly, the quality of the virus differed in the lemon plants and depended upon the kind of inoculum they received. A possible explanation of these reactions is presented later in this paper. In numerous tests lemon seedlings were first infected with psorosis " $\mathrm{A}$ " 
either from non-lesion bark or from bark from typical localized psorosis"A" lesions on sweet orange and then reinoculated from sweet orange seedlings having general "B"-type symptoms (sweet orange I to lemon $1 \mathrm{R}$, fig. 14). Subsequent transfer to healthy sweet orange did not result in early bark symptoms. This demonstrated that in the second inoculation the virus introduced into the previously infected lemon trees did not become established in the same concentration as it did when the same inoculum was used to infect healthy lemon trees.

It has been brought out already that sweet orange trees previously infected and invaded by virus introduced from non-lesion inoculum do not develop early, general bark symptoms when reinoculated from bark-lesion inoculum. However, typical localized bark lesions begin to develop around the sites of reinoculations on such trees one and one-half years or more after transplants of lesion bark have been made to them. The delayed development of bark lesions in protected tissues adjacent to reinoculation sites definitely results from virus introduced in the lesion bark used for reinoculation, but whether the factors involved are quantitative or qualitative is not known. The behavior of trees infected with the lesion-forming type of psorosis in the field and some of the experimental results obtained in these studies, suggest that two virus components are present and that the concentration ratio between the two influences the kind and sequence of symptoms.

Another experiment with lemon trees supports the belief that lesion bark of a psorosis-infected sweet orange tree carries two virus components in a concentration ratio differing from that existing in non-lesion bark. $\mathrm{A}$ lemon seedling originally infected from non-lesion inoculum was reinoculated by means of a transplant of lesion bark from a generally affected sweet orange tree. Four years later, pieces of normal-appearing lemon bark immediately adjacent to the reinoculation site were grafted to sweet orange seedlings, which developed early bark lesions and mature-leaf symptoms. Lemon bark patches taken some distance above the reinoculation site caused only young-leaf symptoms on sweet orange. This demonstrated that the lesion-forming virus from the sweet orange bark graft had invaded the surrounding lemon bark for a short distance in spite of the defense offered by the virus already present in the lemon bark, but not that it was systemically distributed throughout the tree. This reaction is of interest because it occurred in the absence of any bark lesions on lemon, such as those developing on sweet orange tissues around the points of reinoculation.

\section{DISCUSSION}

From these studies it is concluded that psorosis " $\mathrm{B}$ " as originally described by Fawcett (1932) very probably is not caused by a separate and distinct virus strain. If the psorosis-"B"-type symptoms are caused by a virus strain distinctly different from the psorosis-" $A$ " strain, it must be concluded that both exist at all times as a mixture. The basis for this reasoning is that the psorosis-"B" symptoms can always be obtained by infecting healthy sweet orange trees with inoculum taken directly from the localized psorosis-" $\mathrm{A}$ " 
lesions. Furthermore, on experimentally infected trees displaying psorosis"B" symptoms, limbs sometimes develop that have only the "A"-type symptoms, and these yield only the "A" type when transfers of non-lesion inoculum are made from them to healthy sweet orange trees. Although this would at first appear to be a separation of " $\Lambda$ " from " $B$," this is not actually the case, because all " $\Lambda$ "-type infections eventually develop the typical localized lesions from which the "B"-type reaction can always be obtained.

The reactions described in this paper suggest that under natural conditions psorosis "A" comprises two virus strains or components ( $a$ and $b$ ), both of which become systemic in an infected tree. Prior to lesion formation, component $a$, possibly because of its more rapid increase and higher concentration, prevents component $b$ from increasing in concentration to a point sufficient to offset the presence of $a$. A possible explanation of the naturally occurring bark lesions in later years is that component $b$ sometimes invades one or more plant cells ahead of $a$, where it increases in concentration enough to bring about the initial tissue injury leading to lesion formation. Having reached such a concentration, $b$ invades adjacent cells in concentrations high enough to overcome the protection given by component $a$, thus permitting initiation of the bark lesion and its slow enlargement.

The notion that the concentration ratio between components $a$ and $b$ must change before bark lesions can develop is supported by experimentally induced reactions. As described in this paper, lesion bark transplanted to sweet orange trees previously infected and invaded with virus from nonlesion inoculum has no immediate effect. In other words, such previously infected trees are protected against the severe general reaction that follows when healthy sweet orange trees are infected from such inoculum. With time, however, the bark tissues immediately adjacent to the transplanted bark patch are affected, and a slowly enlarging localized lesion develops. Certainly, such lesions on these previously invaded trees are initiated by virus which moves from the lesion inoculum.

The experimental production of slowly developing localized bark lesions on previously invaded sweet orange trees by inoculating with a patch of lesion bark differs from the naturally occurring lesions on infected field trees only in that a small piece of lesion bark is present to initiate the reaction. Although all efforts to demonstrate experimentally the presence of two components in psorosis-" $A$ " infections have failed, the reactions described in this paper can be explained, it seems, only on the basis that this virus consists of two strains or components ( $a$ and $b$ ), both probably capable of inducing young-leaf symptoms, but only one (the $b$ component) being responsible for bark lesions. With such a complex, the localized bark lesions originally described as psorosis "A" represent the kind of lesion induced by component $b$ in tissues already invaded by components $a$ and $b$. Both components are no doubt present systemically in infected trees, but it appears that the concentrations of the two are normally such that $b$ is unable to initiate bark lesions except under special conditions. It is suggested that bark lesions arise when component $b$ by chance invades tissues ahead of 
component $a$ and increases in concentration sufficiently to invade tissues where $a$ is present or to move into newly forming tissues in sufficient strength to become the dominant part of the complex.

When healthy sweet orange trees are inoculated by means of lesion bark, component $b$ finds conditions favorable for rapid increase and soon reaches concentrations sufficient to cause early bark symptoms and lesion development. Inoculations of healthy sweet orange trees by means of non-lesion bark do not result in early bark symptoms. This could be explained on the basis that, in the non-lesion bark tissues, the concentration of component $a$ is higher than that of component $b$, or the two exist in a ratio which permits $a$ to maintain its protection of the tree host against $b$ when the two invade healthy tissue simultaneously.

The different results obtained when lemon trees are inoculated by means of bark from localized lesions on sweet orange, and when they are inoculated by means of bark from sweet orange having the general lesion type of infection, have not been satisfactorily explained. The lemon trees infected from a localized lesion carry a charge of virus differing from that carried by the trees infected from the general lesion type of sweet orange. Actually, on the basis of subtransfer to sweet orange, lemon response is the same, whether inoculation is from a localized lesion or from non-lesion parts of sweet orange. But if the same lesion inoculum is first placed in sweet orange to produce the general reaction and then transferred to lemon, these lemon trees yield inoculum that causes the severe psorosis-"B" type of symptoms on sweet orange.

The explanation presently advanced for these reactions is that in the naturally occurring psorosis-" $A$ " type of lesion the concentration ratio of components $a$ and $b$ is such that when introduced into lemon, which does not develop bark lesions, the two components remain in equilibrium. Upon transfer from such lemon trees to sweet orange, the protective phenomenon operates to prevent lesion development. On the other hand, when inoculum from the localized bark lesion is put into sweet orange which develops bark lesions of psorosis, component $b$ in this host increases rapidly and becomes the dominant part of the virus complex. It retains this dominance when transferred to lemon and is thus capable of causing the severe general reaction upon inoculation from lemon to sweet orange.

Experimental studies of psorosis strains that produce bark lesions are planned with the aim of separating the two suspected virus components discussed in this paper and obtaining additional information regarding the origin and development of bark lesions.

\section{SUMMARY}

Bark patches transplanted from normal-appearing bark of psorosis-"A"infected sweet orange trees to healthy sweet orange trees caused infection which resulted in the appearance of the young-leaf symptoms after four to six weeks. Five years or more after inoculation such trees developed localized scaling bark lesions. Similar inoculations from the same source tree, but using pieces of bark taken from lesion areas, caused the development 
of general bark symptoms, mature-leaf patterns, and twig dieback within a few weeks. This latter source of inoculum produced no such effects when introduced into trees already infected from non-lesion bark inoculum. This protective reaction was used to demonstrate experimentally that psorosis "A," concave gum, blind pocket, crinkly leaf, and infectious variegation are caused by related strains of virus as suggested earlier (Fawcett and Klotz, 1938; Fawcett and Bitancourt, 1943). The tristeza virus provided no protection against psorosis.

Other experimental studies of the virus-strain interference, or crossprotection reaction, demonstrated that although the protection operated as described above to prevent the severe general reaction on reinoculated sweet orange trees it did not protect from later development of localized bark lesions. Two years or more after reinoculations were made, slowly enlarging bark lesions, typical of the naturally occurring lesions of psorosis "A," began to develop around the sites of the transplanted lesion bark. This sequence of lesion development is analogous to that which occurs on infected field trees. It differs from the naturally occurring bark lesions in that the localized lesions which develop on the reinoculated trees at the inoculation sites are clearly initiated by the transplanted lesion bark. Naturally occurring bark lesions develop on infected field trees spontaneously.

In lemon trees, which do not develop psorosis bark lesions, cross protection also operated but lemon responded somewhat differently from sweet orange in regard to the kind of inoculum (lesion or non-lesion) used. Healthy lemon seedlings infected from either lesion or non-lesion bark of a psorosis- "A" sweet orange tree developed the usual young-leaf symptoms but yielded no inoculum of the psorosis-" $B$ " type when inoculation transfers were made to healthy sweet orange. On the other hand, when healthy lemon seedlings were infected by bark transplants from sweet orange trees with psorosis"B"-type symptoms, subsequent transfer from these lemon trees to healthy sweet orange gave the psorosis-"B"-type symptoms. However, if lemon trees were first infected from either lesion of non-lesion bark of typical psorosis" $\mathrm{A}$ " sources and then reinoculated from sweet orange trees having the " $\mathrm{B}$ "type symptoms, inoculum capable of reproducing these symptoms did not become established systemically in the lemon trees. Limited studies indicated that "B"-type inoculum slowly invaded the lemon bark tissues around the point of reinoculation in much the same manner as is believed to occur in the case of reinoculated sweet orange trees.

From these studies, the conclusion is reached that psorosis " $\mathrm{B}$ " does not exist as a distinct strain, or type. The symptom type originally described by Fawcett in 1932 can always be reproduced by infecting sweet orange trees by means of bark transplants from psorosis-"A" lesions. The suggestion is made that the psorosis-"A"-type bark lesion is localized because of the protective effects of virus already systemically distributed through the host tissues before the lesion begins to develop. The psorosis-" $B$ " type of symptoms are the response of a healthy tree to initial infection from lesion inoculum.

It is suggested, further, that psorosis " $\mathrm{A}$ " is normally comprised of two 
virus strains or components, only one of which is capable of causing bark lesions. If this is true, it must be accepted that both components become systemic in infected trees since all sweet orange trees propagated from nonlesion parts of diseased trees will eventually develop bark lesions. The hypothesis is made that bark lesions develop on trees grown from diseased buds only when, by chance, the lesion-forming component invades tissues ahead of the other component. This would permit it to increase in concentration sufficiently to overcome the protection afforded the surrounding tissues by the non-lesion-forming component. The delayed development of localized lesions on the experimentally reinoculated trees supports this hypothesis. So far, all efforts to separate two virus strains from psorosis"A"-infected trees have failed.

\section{LITERATURE CITED}

FAWCETT, H. S.

1932. New angles on treatment of bark diseases of citrus. California Citrog. 17:406-08.

1933. New symptoms of psorosis, indicating a virus disease of citrus. (Abstract) Phytopathology 23:930.

1939. Psorosis in relation to other virus-like eff ects on citrus. (Abstract) Phytopathology 29:6.

FawCEtT, H. S., and A. A. Bitancourt

1943. Comparative symptomatology of psorosis varieties on citrus in California. Phytopathology 33:837-64.

FAwCETt, H. S., and L. C. Cochran

1942. Symptom expression in psorosis of citrus as related to kind of inoculum. (Abstract) Phytopathology 32:22.

FAWCETT, H. S., and L. J. KLOTZ

1938. Types and symptoms of psorosis and psorosis-like diseases of Citrus. (Abstract) Phytopathology 28:670.

1939. Infectious variegation of citrus. Phytopathology 29:911-12.

KLOTZ, L. J., and H. S. FAWCETT

1941. Color handbook of citrus diseases. University of California Press, Berkeley and Los Angeles.

Swingle, W. T., and H. J. Webber

1896. The principal diseases of eitrous fruits in Florida. U. S. Dept. Agr., Div. Veg. Phys. and Path. Bul. 8.

WALLACE, J. M.

1945. Technique for hastening foliage symptoms of psorosis of eitrus. Phytopathology 35:535-41.

1947. The use of leaf tissue in graft-transmission of psorosis virus. Phytopathology 37: 149-52. 
The journal Hilgardia is published at irregular intervals, in volumes of about 600 pages. The number of issues per volume varies.

Subscriptions are not sold. The periodical is sent as published only to libraries, or to institutions in foreign countries having publications to offer in exchange.

You may obtain a single copy of any issue free, as long as the supply lasts; please request by volume and issue number from:
Agricultural Publications
Room 22, Giannini Hall
University of California

\section{Berkeley 4, California}

The limit to nonresidents of California is 10 separate issues on a single order. A list of the issues still available will be sent on request. 


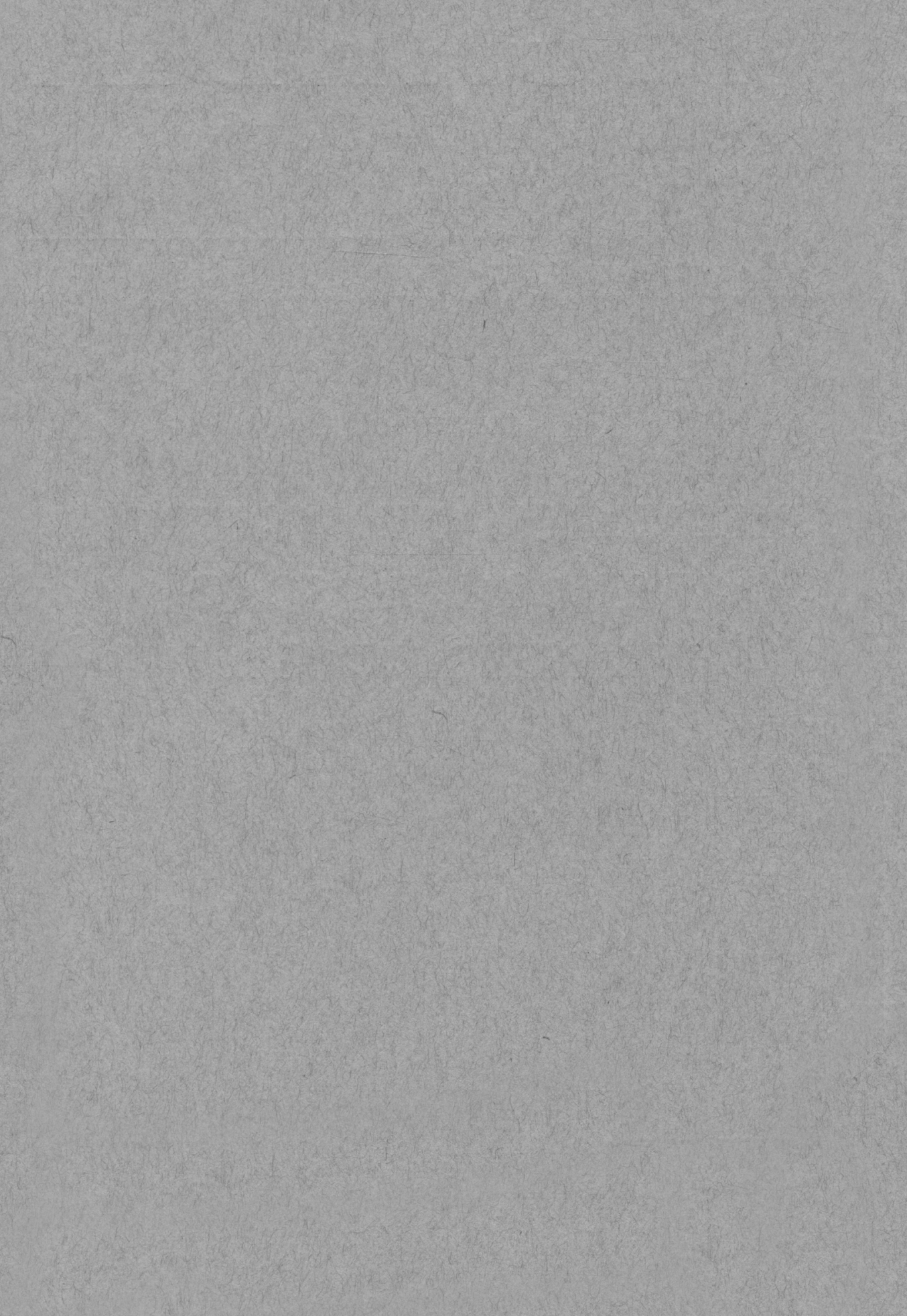

